\title{
Quasistatic and dynamic compression of aluminum-oxide particle reinforced pure aluminum
}

\author{
C. San Marchi ${ }^{\mathrm{c}, *}$, Fahe $\mathrm{Cao}^{\mathrm{b}}$, M. Kouzeli ${ }^{\mathrm{c}}$, A. Mortensen ${ }^{\mathrm{a}}$ \\ ${ }^{a}$ Laboratory for Mechanical Metallurgy, Ecole Polytechnique Fédérale de Lausanne (EPFL), CH-1015 Lausanne, Switzerland \\ ${ }^{\mathrm{b}}$ Inner Mongolia Institute of Metal Research, P.O. Box 4, Baotou, Inner-Mongolia 014034, PR China \\ ${ }^{\mathrm{c}}$ Department of Materials Science and Engineering, Northwestern University, 2225 N. Campus Dr., Evanston, IL 60208-3018, USA
}

Received 25 September 2001; received in revised form 3 January 2002

\begin{abstract}
Pure aluminum matrix composites reinforced with $40-55$ vol. $\% \mathrm{Al}_{2} \mathrm{O}_{3}$ particles of various sizes $(5,10,29$, and $58 \mu \mathrm{m})$ are produced by gas-pressure infiltration. Comparison of compressive flow stresses of these composites at quasistatic and dynamic strain rates shows that, in accord with the literature, the increase in flow stress of dynamically compressed composites results from the sensitivity of the matrix to strain rate. The accumulation of damage in the composites is quantified through high-precision density measurements. Damage accumulates primarily as a function of strain due to particle cracking followed by separation of the broken-particle segments and, to a lesser extent, by matrix cavitation. Composites reinforced by smaller particles have a higher flow stress, lower strain-rate sensitivity, and accumulate less damage, while a greater concentration of reinforcement increases the flow stress, strain-rate sensitivity, and the rate of damage accumulation. (C) 2002 Elsevier Science B.V. All rights reserved.
\end{abstract}

Keywords: Particle-reinforced aluminum composites; Mechanical properties: plastic; High strain rate; Damage

\section{Introduction}

Metal matrix composites for structural applications are potentially subject to dynamic loading. Thus the effect of strain rate is an important consideration for a complete understanding of deformation processes in these materials. Investigations of the dynamic deformation of reinforced metals at room temperature include a diverse range of whisker, short fiber and particlereinforced aluminum matrix composites, typically with ceramic concentrations of $25 \mathrm{vol} . \%$ or less [1-32]. In the present work, the strain-rate sensitivity of composites containing more than $40 \mathrm{vol} \%$ ceramic particles is explored.

A critical review of the dynamic mechanical properties reported in the literature (for strain rates $<5000$ $\mathrm{s}^{-1}$ ) shows that the dependence of the composite flow stress on strain rate is similar to that of the unreinforced matrix $[1,2,10-23]$. In other words, composites with a

\footnotetext{
* Corresponding author. Tel.: +1-847-491-7794; fax: +1-847-4676573

E-mail address: c-sanmarchi@northwestern.edu (C. San Marchi).
}

strain-rate sensitive matrix are also strain-rate sensitive, while matrix metals that are not sensitive to strain rate result in composites that are not sensitive to strain rate. On the other hand, finite-element calculations show that strong constraint and localization imposed by the reinforcement on the distribution of plastic flow in the matrix result in potential enhancements in strain-rate sensitivity for a composite compared to the unreinforced matrix [33]. While that work assumed spherical reinforcements, it was later extended to other shapes of reinforcement [34], leading to the same conclusions.

Microstructural damage, usually associated with the reinforcement, also plays an important role in the deformation of metal matrix composites at both low and high rates of deformation. Intensified damage in the form of reinforcement fracture is documented in some whisker-reinforced systems as the strain rate is increased $[9,18,19,21,24]$, but less clear trends are found for particle-reinforced systems $[11,18,28]$. A damage function was recently introduced into constitutive equations to account for damage at high strain rates assuming that the damage accumulation as a function of strain is independent of strain rate [28]. 
Table 1

Characteristics of composites produced in this study

\begin{tabular}{llll}
\hline Composite designation & FEPA $^{\mathrm{a}}$ powder designation & Particle size $(\mu \mathrm{m})$ & $\mathrm{Vol}_{.} \% \mathrm{Al}_{2} \mathrm{O}_{3}( \pm 1)$ \\
\hline $58 \mathrm{~A}$ & $\mathrm{~F} 220$ & 58 & 44 \\
$29 \mathrm{~A}$ & $\mathrm{~F} 320$ & 29 & 43 \\
$10 \mathrm{~A}$ & $\mathrm{~F} 600$ & 9.3 & 55 \\
$5 \mathrm{~A}$ & $\mathrm{~F} 1000$ & 4.5 & 40 \\
\hline
\end{tabular}

a Federation of the European Producers of Abrasives, FEPA-standard 42-1894 R 1993.

In the present study, a significant strain-rate sensitivity is demonstrated for infiltrated composites that contain more than 40 vol. $\% \mathrm{Al}_{2} \mathrm{O}_{3}$ particles in a pure aluminum matrix. The influence of particle size and matrix flow stress on internal damage accumulation is characterized by measuring changes in density before and after testing, and compressive flow stresses are compared to tensile data for the same material from Ref. [35].

\section{Materials and experimental procedures}

\subsection{Material production}

Alumina-reinforced aluminum composites were prepared by gas-pressure infiltration using $99.99 \%$ pure aluminum and $\alpha-\mathrm{Al}_{2} \mathrm{O}_{3}$ particles. The reinforcement (from Treibacher Schleifmittel, Laufenburg, Germany) was received in standard abrasive grades (FEPA-specified size distributions) and has an angular morphology.

Details of the gas-pressure infiltration process are discussed elsewhere [36]. In this study, preforms were prepared in air by tapping dry powder into graphitecoated alumina crucibles. After adding a billet of metal to the crucible on top of the preform, this assembly was evacuated and heated to $750{ }^{\circ} \mathrm{C}$. Pressurized argon at 8 $\mathrm{MPa}$ was used for infiltration, after which the composite was directionally solidified. Preforms from four narrow distributions of particle size were infiltrated to produce the composites listed in Table 1.

The cast composites feature uniformly distributed $\mathrm{Al}_{2} \mathrm{O}_{3}$ particles in a pore-free matrix, Fig. 1. The particle distribution is determined by the particle-particle contacts as a consequence of dense packing of the $\mathrm{Al}_{2} \mathrm{O}_{3}$ particles during preform preparation. The tap density of the powder determines the volume fraction ceramic in the composite and is a function of the average shape and size distribution of the particles.

\subsection{Mechanical testing}

Cylindrical test specimens were machined from the ascast composites using electro-discharge machining. The same nominal geometry was used for both dynamic and quasistatic compression tests: $7 \mathrm{~mm}$ in length and $8 \mathrm{~mm}$ in diameter. A screw-driven universal testing machine was used to perform quasistatic compression tests at constant cross-head speed with an initial strain rate of $1.4 \times 10^{-4} \mathrm{~s}^{-1}$.

A conventional split Hopkinson pressure bar (SHPB) was used for dynamic compression tests at nominal strain rates between 500 and $3000 \mathrm{~s}^{-1}$ (a detailed description of the SHPB technique can be found in Ref. [37]). The strain rate was varied primarily by varying the velocity of the striker bar. All testing was performed at room temperature with sufficient lubrication to prevent barreling in the specimens. In addition, some specimens were reloaded after dynamic testing using the same procedure as for quasistatic testing. The unreinforced matrix metal was not tested because: (i) even if processed analogously it is microstructurally different from the composite matrix (grain sizes are on the order of a centimeter and the initial dislocation density differs considerably); and (ii) extensive data for bulk pure aluminum exist in the literature [38-43].

It has been shown that nearly all plastic work during SHPB testing is converted into heat [44] and corrections for adiabatic heating in aluminum can be significant at high strains [45]. The adiabatic temperature rise at 5\% strain for the 10A material, however, is estimated to be less than $5 \mathrm{~K}$. The other materials have lower flow stresses, thus adiabatic heating is less still. As the deformation increases, more heat is generated and the flow stress of the composite may be affected, thus in what follows all comparisons are made at relatively low strains, where such corrections tend to be small and can be neglected.

\subsection{Microstructural characterization}

The microstructure of the as-cast composites was characterized by optical and scanning electron microscopy. Specimens were prepared for metallography after Ref. [46]. Tested specimens were sectioned parallel to the loading direction and polished for identification of microstructural damage.

Damage accumulation was monitored through density measurements based on Archimede's principle with distilled water as the immersion fluid. A microbalance with sensitivity of $0.01 \mathrm{mg}$ was used to ensure density measurements within $0.01 \%$. For dynamically tested 


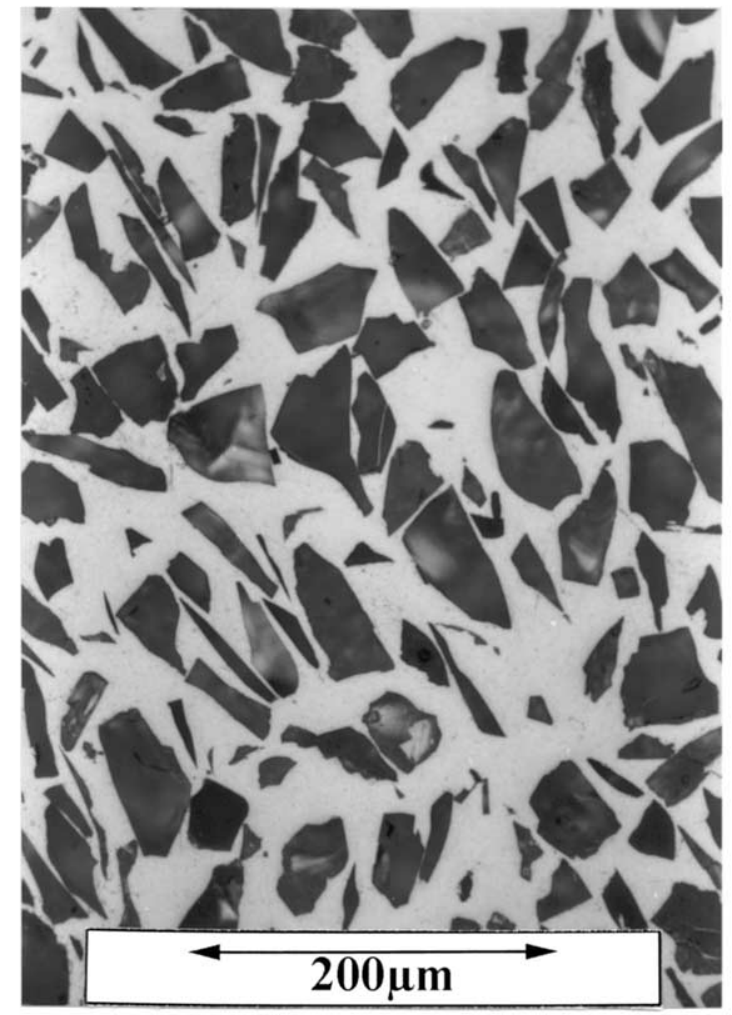

(a)

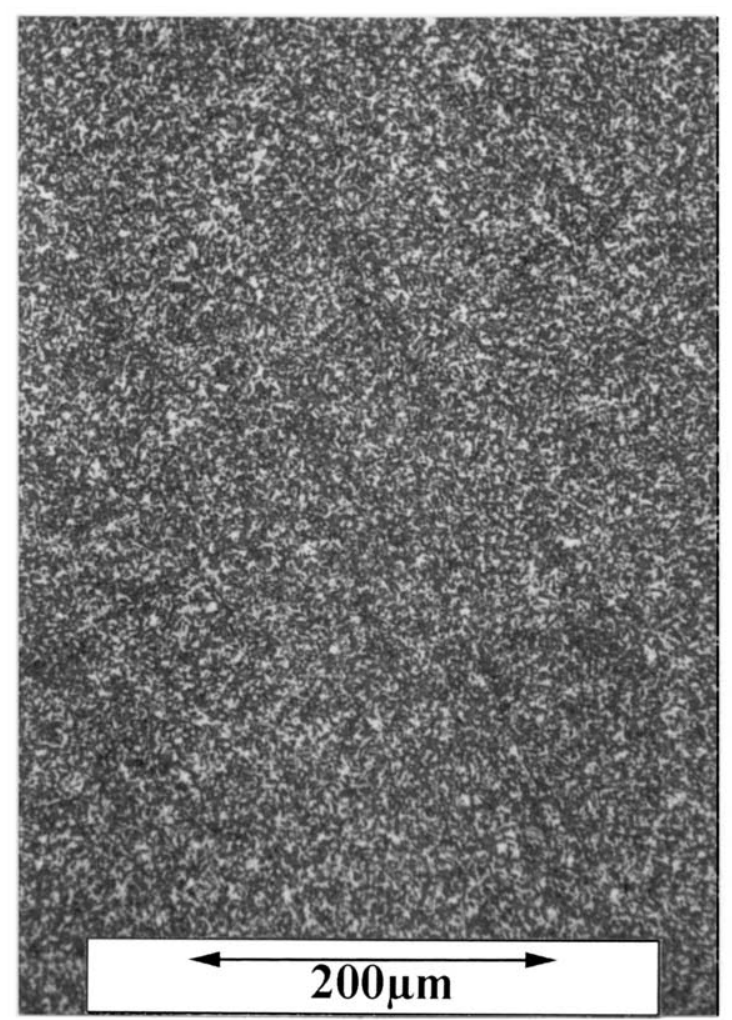

(b)

Fig. 1. Optical micrograph of as-cast microstructure: (a) 58A; and (b) $5 \mathrm{~A}$. specimens the density was measured before and after compression. For specimens tested at low strain rates the density was measured before and after compression to a specific deformation. This procedure was repeated such that the change in density for the composites could be determined as a function of the accumulated plastic strain. Damage monitoring in the quasistatic tests was performed on at least two specimens utilizing different strain increments to verify that damage measurements are not dependent on the magnitude of the strain increment.

The volume fraction of reinforcement in the as-cast composites was also determined from the density measurements, assuming that the composite is initially pore-free and that the densities of aluminum and alumina are 2.6989 and $3.97 \mathrm{~g} \mathrm{~cm}^{-3}$, respectively. The average reinforcement content is listed in Table 1 for each material; the materials are specified by the nominal particle size in micrometers and the letter $\mathrm{A}$, which refers to the abrasive-grade $\mathrm{Al}_{2} \mathrm{O}_{3}$ reinforcement.

\section{Results}

\subsection{Compressive deformation}

Quasistatic compressive flow curves show that the composite flow stress increases significantly as the average particle size is decreased, Fig. 2(a), with the exception that the flow stress of the $10 \mathrm{~A}$ material is greater than for the $5 \mathrm{~A}$ material. The volume fraction of particles is also significantly higher in the $10 \mathrm{~A}$ material compared to the 58A, 29A, and 5A materials, Table 1 : the $10 \mathrm{~A}$ material contains $55 \mathrm{vol} . \%$ ceramic while the other three contain on average 42 vol. $\%( \pm 3)$.

The flow stress reaches a nominal plateau near $10 \%$ strain, and eventually begins to decrease at higher strains: the $10 \mathrm{~A}$ material reaches a maximum near $12 \%$ strain, while the $29 \mathrm{~A}$ material does not reach a maximum until near $40 \%$ strain. The $29 \mathrm{~A}$ material was compressed to strains of $75 \%$ without failure. The $5 \mathrm{~A}$ and $10 \mathrm{~A}$ materials, on the other hand, sometimes fractured in compression along planes approximately $45^{\circ}$ to the loading axis as described for a whiskerreinforced composite in Ref. [21].

Dynamic compression increases the flow stress of all of the composites. Fig. 2(b) shows the stress-strain relationship for materials compressed at strain rates of about $2000 \mathrm{~s}^{-1}$. Dynamically deformed specimens reload (under quasistatic conditions) to their quasistatic flow stress at equivalent strain after a small transient at slightly higher stress, Fig. 3.

The flow stress at 5\% strain is plotted in Fig. 4 as a function of strain rate. The choice of 5\% strain is made so as to avoid perturbations due to the stress-strain transients in the first instants of impact during SHPB 

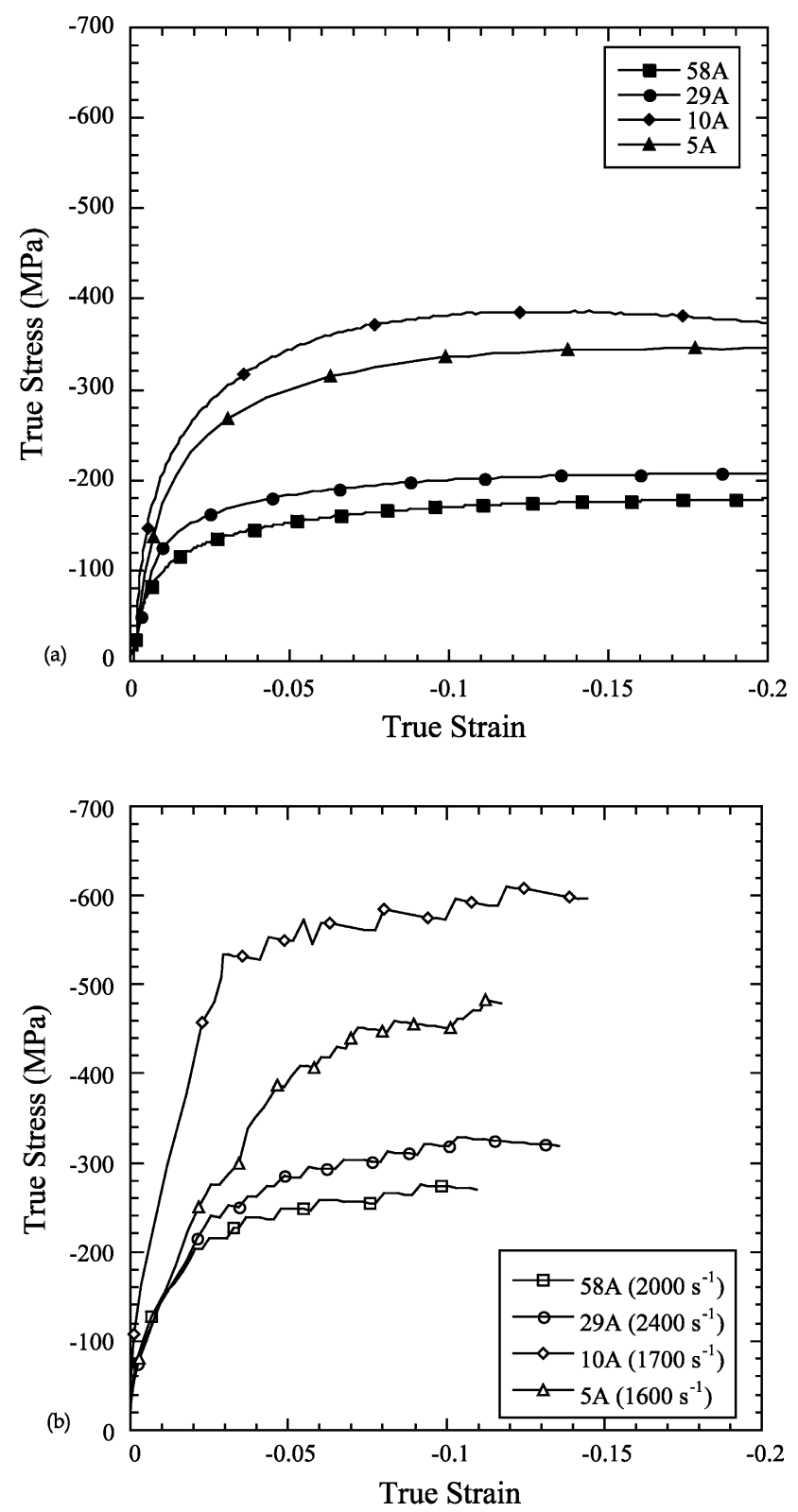

Fig. 2. Compressive stress-strain behavior of the present composites: (a) quasistatic compression $\left(10^{-4} \mathrm{~s}^{-1}\right)$; (b) dynamic compression.

testing, following recommendations in Ref. [20]. Higher strains are not used to minimize the effects of damage accumulation and, as mentioned, of adiabatic heating.

\subsection{Internal damage}

Optical metallography of compressed specimens shows that microstructural damage is dominated by particle cracking, as was previously observed in these materials subjected to tensile loading [46]. The fraction of broken particles increases with strain and is qualitatively similar in samples of the same material subjected to both quasistatic and dynamic compression. Particles break primarily parallel to the loading direction and this

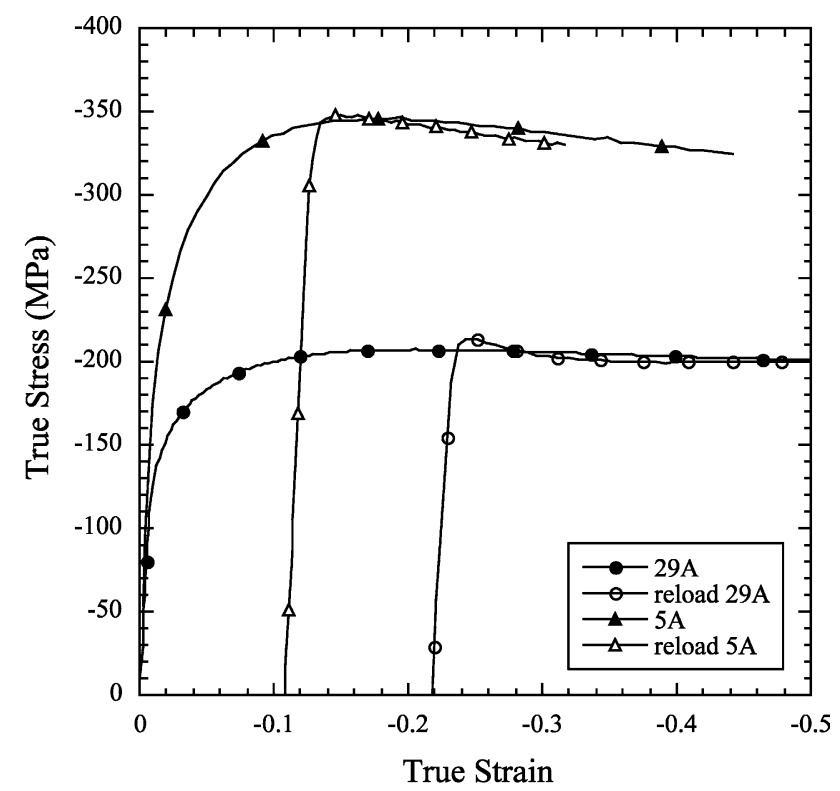

Fig. 3. Quasistatic reloading response $\left(10^{-4} \mathrm{~s}^{-1}\right)$ of $29 \mathrm{~A}$ material (previously strained at $2400 \mathrm{~s}^{-1}$ ) and 5A material (previously strained at $1600 \mathrm{~s}^{-1}$ ) compared with quasistatic compression.

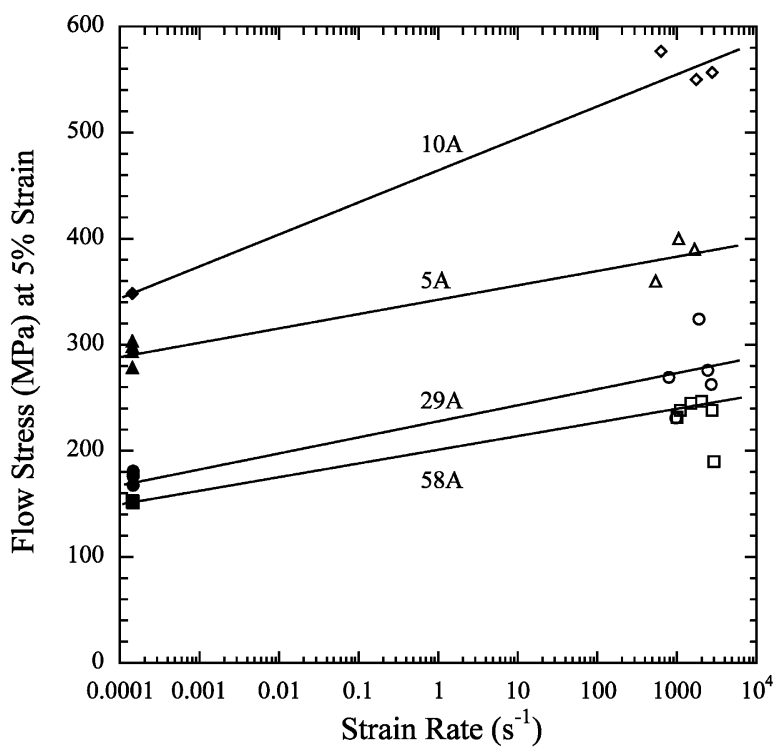

Fig. 4. Measured composite flow stress at $5 \%$ strain as a function of strain rate.

appears to be activated by stresses transferred to the particles across particle-particle contacts, Fig. 5.

In the $10 \mathrm{~A}$ and $5 \mathrm{~A}$ materials, matrix cavitation was also observed in the regions where the matrix is most constrained by the particles, Fig. 6. The relative importance of particle cracking and matrix cavitation, however, is very different between these two materials: the 5A material has fewer broken particles compared to the $10 \mathrm{~A}$ (and all other) material.

Accumulation of damage is quantified through the damage parameter $D_{\rho}$ defined as the change in density of the material with strain: 


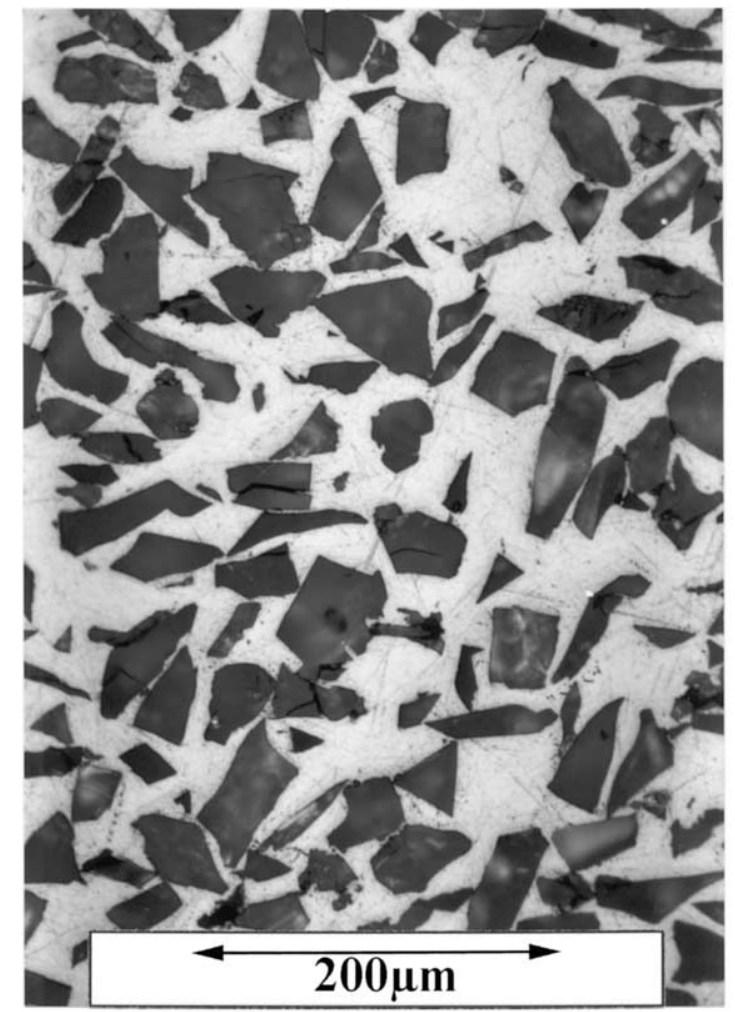

(a)

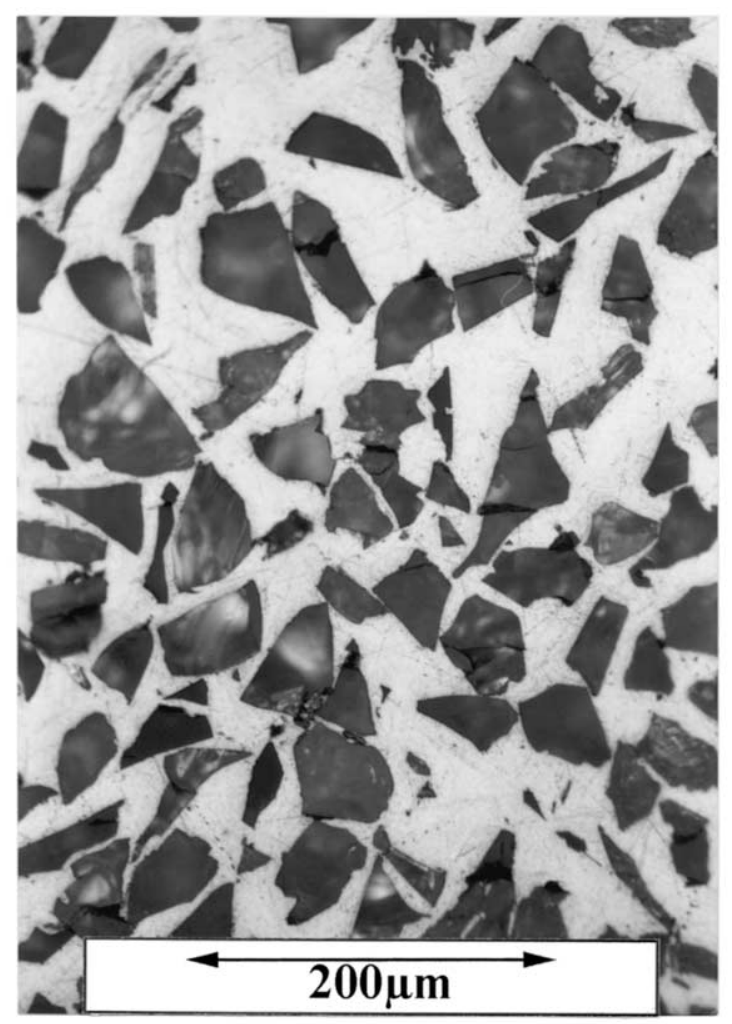

(b)

Fig. 5. Particle fracture in 58A material after: (a) quasistatic compression; and (b) dynamic compression. In both micrographs, the compressive loading direction is nominally along the horizontal.

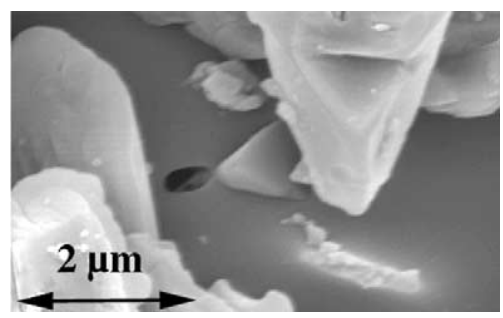

Fig. 6. Matrix cavitation in 5A material after quasistatic compression.

$D_{\rho}=1-\left(\frac{\rho}{\rho_{0}}\right)$,

where $\rho_{0}$ is the initial density and $\rho$ is the density of a specimen after an applied strain increment. This damage parameter is plotted for quasistatic and dynamic compression as a function of strain in Fig. $7(a-d)$. It is found that the difference in the rate of internal damage accumulation between quasistatic and dynamic straining is small, and tends to increase for materials with larger particles. Such a difference is clearly evident only for the $58 \mathrm{~A}$ material, which is reinforced with the largest of the particles that were used in this study.

\section{Discussion}

\subsection{Quasistatic flow stress}

The flow stress in particle reinforced metals is known to increase as the average interparticle distance is decreased [47-50]. This size effect is seen in tensile deformation of the present composites [35], and is shown to be quantitatively in accord with geometrically necessary dislocation analysis [51]. For the three composites (58A, 29A, and 5A) containing an average of 42 vol. $\%$ ceramic the flow stress measured here at $5 \%$ compressive strain matches, within experimental uncertainty, the effective tensile flow stress at the same strain in the absence of damage (derived using postulates of continuum damage mechanics, and data from tensile tests and damage measurements on the same material at a nominal strain rate of $10^{-4} \mathrm{~s}^{-1}$ ) cf. Fig. 2a and Ref. [35]. Thus, for these three materials the difference in compressive flow stress can be related to the interparticle spacing.

The 10A material exhibits the same trends as for the other materials in flow stress, strain-rate sensitivity and damage; however, it is distinguished by a higher fraction ceramic resulting in somewhat different quantitative results. Thus, a comparison of the $10 \mathrm{~A}$ material to the $58 \mathrm{~A}, 29 \mathrm{~A}$ and $5 \mathrm{~A}$ materials is deferred to the final section of the discussion. 

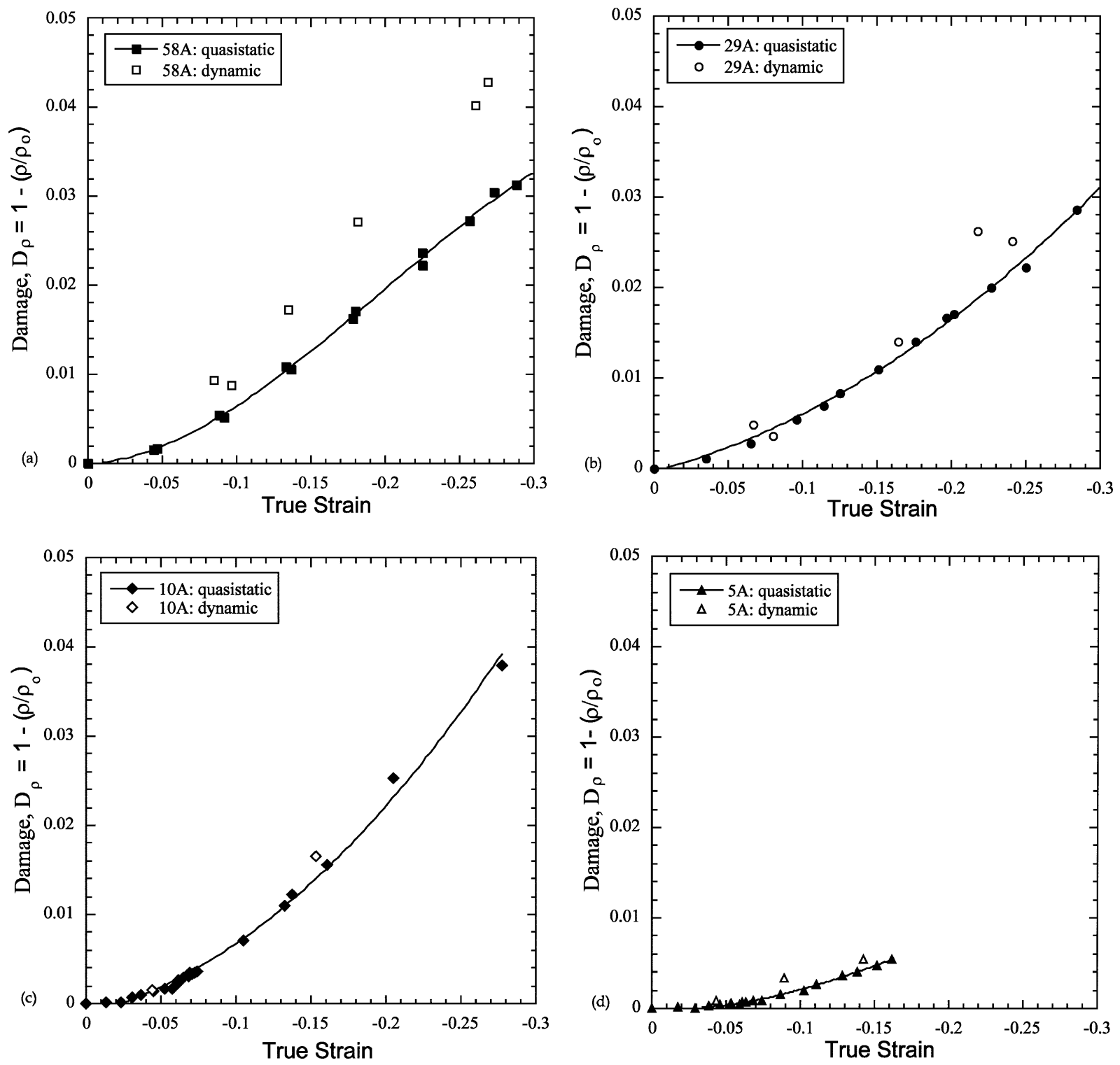

Fig. 7. Comparison of damage accumulation in composites due to quasistatic and dynamic compression: (a) 58A material; (b) 29A material; (c) 10A material; (d) 5A material.

\subsection{Strain-rate sensitivity}

We provide in Fig. 8 an overview of data on the strain-rate sensitivity of aluminum, its alloys, and its composites, including results from published work and from the present study, plotted in terms of a strain-rate sensitivity parameter $\Sigma$ similar to that used in Refs. $[42,52-55]$ :

$\Sigma=\frac{\sigma_{\mathrm{d}}-\sigma_{\mathrm{s}}}{\sigma^{*}} \frac{1}{\ln \left(\dot{\varepsilon}_{\mathrm{d}} / \dot{\varepsilon}_{\mathrm{s}}\right)}$,

where $\sigma$ is the flow stress at $5 \%$ strain and $\dot{\varepsilon}$ is the strain rate with subscripts $d$ and $s$ referring to conditions of dynamic and quasistatic testing, and the asterisk refers to a reference strain rate of $10^{-3} \mathrm{~s}^{-1}$. At strain rates greater than about $10^{4} \mathrm{~s}^{-1}$, the flow stress of most metals (at constant strain) increases more rapidly than at lower strain rates; however, the onset of this transition is not always clear, thus, data from the literature for materials tested at strain rates greater than $5 \times 10^{3} \mathrm{~s}^{-1}$ were not used in Fig. 8. Results from prior studies of the dynamic deformation of precipitation-hardened aluminum matrix composites, in which the unreinforced matrix and the composite were both characterized, appear as data points linked by a tie-line in Fig. 8 .

Several authors have used finite-element models to study dynamic deformation of aluminum matrix composites using a matrix flow law of the form: 


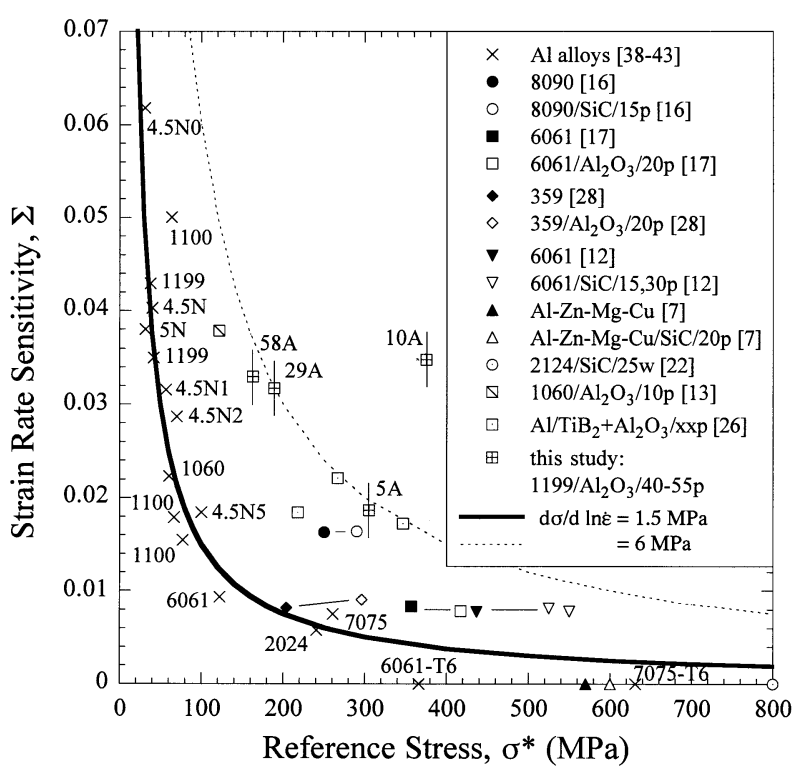

Fig. 8. Relative strain rate sensitivity $\Sigma$ of some aluminum alloys and aluminium matrix composites ( $\sigma^{*}$ is the flow stress at $5 \%$ strain and $\left.\dot{\varepsilon}=10^{-3} \mathrm{~s}^{-1}\right)$. Alloy designations are given for data from Refs. [38$43]$ in the $\mathrm{O}$ temper except where noted $(5 \mathrm{~N}=99.999 \%$ pure $\mathrm{Al}$, $4.5 \mathrm{~N}=99.995 \%$ pure $\mathrm{Al}$, and $4.5 \mathrm{~N} 0,4.5 \mathrm{~N} 1,4.5 \mathrm{~N} 2$ and $4.5 \mathrm{~N} 5$ are coldworked to $0,10,20$ and $50 \%$, respectively from Ref. [39]).

$\sigma=k \varepsilon^{1 / n}\left[1+\left(\frac{\dot{\varepsilon}}{\dot{\varepsilon_{0}}}\right)^{m}\right]$

where for bulk aluminum $k, n, m$, and $\dot{\varepsilon}_{0}$ are material constants (and neglecting the elastic component of strain) $[17,33,34]$. These studies concluded that aluminum matrix composites should be significantly more strain-rate sensitive than the bulk metal and that this effect increases with increasing strain rate and fraction of reinforcement. The observation that several composites display approximately the same $\Sigma$ as their matrix, Fig. 8 (as opposed to the enhanced sensitivity predicted) has been interpreted as a consequence of microstructural damage [28].

In a published study conducted on high-purity $(99.995 \%)$ aluminum the difference in flow stress between strain rates of $10^{-4}$ and $10^{3} \mathrm{~s}^{-1}$ was measured to be approximately constant at $26 \mathrm{MPa}$ for various levels of cold work $(0,10,20$ and 50\%) [39]. Other data for pure aluminum and its alloys show approximately the same difference in flow stress between these strain rates $[38,40-43]$. This is evidence that in pure aluminum at strain rates less than about $10^{3} \mathrm{~s}^{-1}$, the absolute increase in flow stress $(\Delta \sigma)$ with increasing strain rate is independent of the yield stress, i.e. independent of the dislocation density $[42,52,53]$. Eq. (3) in comparison assumes that the relative increase in flow stress $\left(\sigma_{\mathrm{d}} / \sigma_{\mathrm{s}}\right)$ is independent of the yield stress and is thus not appropriate for pure aluminum. Flow behavior of aluminum can be described by a simple semi-logarithmic relationship: $\sigma=\sigma_{0}+\sigma_{1} \ln \dot{\varepsilon}$

where $\sigma_{0}$ is the athermal friction stress (which depends on strain, i.e. on the level of prior work hardening but not on strain rate), and $\sigma_{1}$ is a constant related to the thermally activated mechanism governing dislocation glide $[38,55,56]$. The strain-rate sensitivity parameter $\Sigma$ then decreases as the flow stress increases: similar comparisons and trends have been noted previously for aluminum alloys [42,52-54] and for steels [55]. Experimental data show furthermore that $\sigma_{1}$ is relatively constant and equal to $1.5 \mathrm{MPa}$ for a number of aluminum alloys (including pure aluminum), as shown by the bold line in Fig. 8 and as noted in previous studies [38,42,56].

In the present study, a result similar to that observed for cold worked aluminum is obtained with the composites. The difference in flow stress between quasistatic $\left(10^{-4} \mathrm{~s}^{-1}\right)$ and dynamic strain rates near $10^{3} \mathrm{~s}^{-1}$ is approximately $80 \mathrm{MPa}$ for the three composite materials with nominally the same volume fraction reinforcement (58A, 29A, and 5A). This is evident by the similar slopes in Fig. 4 for these three materials, in which the matrix differs primarily in dislocation density as described in Section 4.1.

When reloaded at a low strain rate, the flow curve of the dynamically-tested specimens essentially rejoins the quasistatic flow curve, Fig. 3. The findings that the absolute increase in composite flow stress due to dynamic deformation is constant and that the quasistatic flow stress is not changed considerably by prior dynamic loading show that the strain-rate sensitivity of the present composites is not linked with microstructural differences such as reinforcement size or damage accumulation; it is rather a result of variations in the intrinsic mobility of dislocations in the pure aluminum matrix.

There is a small transient of higher flow stress upon quasistatic reloading of dynamically compressed specimens, Fig. 3. Transients of this type have been observed previously for pure aluminum [41] and attributed to strain-rate history effects, which are well known for this metal [38,57]. This slight temporary increase in flow stress manifests a difference in the dislocation substructure developed during high and low rate deformation. Qualitative differences in dislocation substructures as a consequence of quasistatic and dynamic deformation were indeed found in a low volume fraction composite with a pure aluminum matrix [14] (there is significant risk of producing artifacts when preparing TEM specimens from metal matrix composites, particularly with unalloyed aluminum [58]; hence direct observation of dislocation structures was not pursued in this study).

The present observations are interpreted in terms of a composite flow law after Eq. (4) with $\sigma_{1}$ equal to about 6 $\mathrm{MPa}$, as shown in Fig. 8. The increase in the apparent 
value of $\sigma_{1}$, from 1.5 $\mathrm{MPa}$ in unreinforced aluminum to $6 \mathrm{MPa}$ in the composite, can be attributed to loadbearing by the particles which tends to amplify, in the composite flow stress, any increase in the matrix flow stress. An increase by a factor of 4 is somewhat surprising, since at quasistatic strain rates these composites display a flow stress that is less than twice that of the matrix [51]. $\sigma_{1}$ is estimated from data at the extremes of the validity of Eq. (4), however, rendering its value somewhat uncertain. It is also noted that other data in the literature for (nominally) pure aluminum matrix composites show an equally high $\Delta \sigma / \Delta \ln \dot{\varepsilon}$ (Fig. 8) despite the lower volume fractions ceramic. Quantitative explanations of these trends would require micromechanical analysis pertinent to a matrix that obeys Eq. (4) instead of Eq. (3).

\subsection{Damage}

The damage micromechanisms observed in these composites, namely particle cracking and matrix cavitation in narrow interparticle regions, are in accord with previous studies on particle reinforced metals. In particular, particle cracks are oriented parallel to the imposed stress axis (and are as a consequence perpendicular to a principal tensile stress axis) as in Refs. [5961]. Particle fracture can be attributed to particleparticle interactions, as was found for these composites in tension [35,46], and as noted also for short fiber composites [22].

Previous studies of particulate metal matrix composites in tension have shown that the accumulation of damage can be characterized by the change in density of the material with strain $[46,62,63]$ and that this change can be related to other damage measures such as change in stiffness $[46,64,65]$. In compression, since particle fracture is predominately perpendicular to the principal tensile axes, the segments of the broken particle can move apart following the deformation of the material

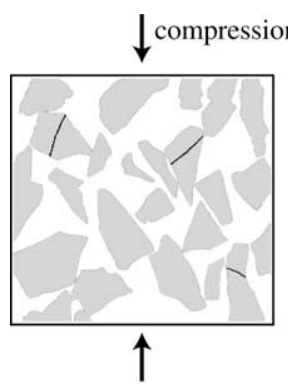

(a)

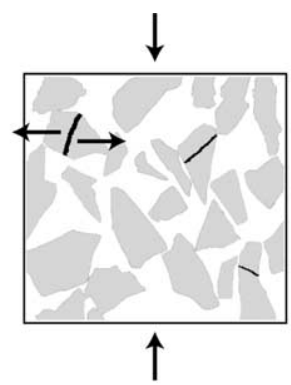

(b)
Fig. 9. Schematic diagram of void growth due to separation of the segments of cracked particles: (a) loads are transferred at interparticle contact points and produce stress concentrations ultimately cracking the particles; (b) the segments of the cracked particles open due to nominal tensile stresses perpendicular to the applied load. around them, as shown schematically in Fig. 9. Thus a void is created (distinct from matrix cavitation) and grows in compression, causing a continuous change in the density of the material with deformation, and in turn allowing the use of densitometry to monitor damage evolution in the material.

The basic trend of decreasing damage with decreasing particle size, Fig. 7, is consistent with what is found in prior work on particle reinforced metals tested at low strain rates [66-73], and also in particle-bed comminution processes where particle fracture is initiated in compression by particle-particle interactions [74,75]. Except for the composite with the largest particles (58A), the nature and level of damage is the same for dynamic and quasistatic compression, Fig. 7, in concurrence with Ref. [28]: a higher matrix flow stress does not result in significantly more internal damage at a given strain. This differs from results of quasistatic testing of low volume fraction particle reinforced aluminum composites that accumulate damage either by matrix cavitation [76] or by particle cracking [6871,77], where an increased matrix flow stress results in an increased rate of damage accumulation.

This significant difference between high ( $\geq 40$ vol. $\%$ as studied here) and low ( $<20$ vol. $\%$ as found in the literature) volume fraction composites can be rationalized by consideration of their different microstructures. In metals reinforced with isolated particles, the applied stress is transferred to the particles primarily by the matrix, hence a higher matrix flow stress results in more fractured particles. In high volume fraction composites, on the other hand, and especially in compression, stress can be transferred directly from one particle to another across contact points where peak particle stresses are expected to be found. This explains the observation that damage accumulation depends primarily on strain in the present composites and significantly less on the matrix flow stress.

\subsection{Effect of volume fraction}

The 10A material, which is distinguished from the three other composites by a higher fraction ceramic ( 55 versus 42 vol.\%), exhibits a compressive flow stress that significantly exceeds its flow stress in tension [35]. It appears unlikely that this tension-compression asymmetry in the 10A material would be caused by residual stresses, by sample friction with the platens, or by internal damage accumulation, since these would similarly affect the 58A, 29A and 5A materials (which do not display such a tension-compression asymmetry).

This difference in behavior as a function of particle volume fraction may perhaps result from a difference in the relative stability of the network of touching ceramic particles to loading. At higher fractions ceramic, there are more interparticle contact points per particle [78] 
resulting in a more rigid network of particles since the motion of one particle relative to another is more constrained by its neighbors during deformation (in the terminology of the science of powder media: 'rearrangement' is more difficult). The flow stress of the ceramic particle bed, and hence the composite, should for this reason have a greater dependence on the hydrostatic stress component in the $10 \mathrm{~A}$ material than in the other three composites (as manifest for example in yield criteria for packed particle beds, such as the Drucker-Prager criterion). The increased level of damage accumulation at large strains in the 10A material compared with the other materials may also be a result of a greater number of interparticle contacts, i.e. a greater number of sites where particle fracture can be initiated and relative particle motion is hindered.

The 10A material displays greater strain-rate sensitivity compared to the other composites, Figs. 4 and 8 . The general trend of increased strain-rate sensitivity for larger fractions of reinforcement is in qualitative agreement with predictions of modeling from the literature $[17,33,34]$, but, as mentioned above, quantification of this effect would require micromechanical analysis pertinent to a matrix that displays a constant $\Delta \sigma / \Delta \ln \dot{\varepsilon}$ regardless of its level of hardening. We note in passing the possibility that the intrinsic strain-rate sensitivity of alumina [79] may contribute to the strain-rate sensitivity of the present composites: this effect would certainly be greater in the $10 \mathrm{~A}$.

\section{Conclusions}

The compressive flow stress of $\mathrm{Al}_{2} \mathrm{O}_{3}$ particle-reinforced high-purity aluminum matrix composites produced by infiltration is a function of the average particle diameter $(58,29,10$ and $5 \mu \mathrm{m})$ and the concentration of reinforcement (40-55 vol.\%). At a volume fraction ceramic near $42 \%$, the flow stress is similar in tension and compression. As in tension, the compressive flow stress is greater for composites with smaller particles, a consequence of matrix hardening by geometrically necessary dislocations. At higher fractions of reinforcement, data suggest there is a change in matrix-reinforcement load partitioning between tension and compression.

Dynamic compression tests performed in this study show that the absolute increase in the composite flow stress at high strain rates (near $1000 \mathrm{~s}^{-1}$ ) is higher than that found for high-purity aluminum; it is also independent of particle size for the same volume fraction. These observations, together with the quasistatic reloading behavior of dynamically loaded specimens, show that the observed increase in composite flow stress with strain-rate can be attributed to the thermally activated mechanisms governing dislocation glide in the matrix.
Damage accumulates in these composites as the compressive strain increases, predominantly by particle cracking parallel to the compression direction and to a lesser extent by matrix voiding in regions of high triaxiality. The rate of damage accumulation (as measured by the density-derived damage parameter $D_{\rho}$ ) increases for larger particles and higher volume fractions of ceramic. Except with the largest particle size, the higher matrix flow stress at high strain rates does not significantly alter the dependence of damage on strain. This is because, unlike low-concentration composites, particle-particle interactions dominate fracture of the reinforcement in these high-volume fraction particlereinforced composites.

\section{Acknowledgements}

This work was supported by the Swiss National Science Foundation under Contract No. 20-55291.98, by core funding of the Laboratory for Mechanical Metallurgy at EPFL, and by a one-year grant from the Chinese Government for the stay of one of the authors (Fahe Cao) at EPFL. The authors also wish to thank Shiyu Tian who performed the dynamic compressive tests at the Inner Mongolia Institute of Metal Research.

\section{References}

[1] J. Harding, M. Taya, B. Derby, S. Pickard, Sixth International Conference on Composite Materials, ICCM 6, London, 1987, Elsevier Applied Science, London, 1987, p. 2.224.

[2] S.M. Pickard, B. Derby, J. Harding, M. Taya, Scripta Metall. 22 (1988) 601.

[3] K. Cho, S. Lee, Y.W. Chang, J. Duffy, Metall. Trans. 22A (1991) 367.

[4] S.I. Hong, G.T. Gray, III, J.J. Lewandowski, Scripta Metall. Mater. 27 (1992) 431.

[5] K.-M. Cho, S. Lee, W.B. Choi, I.-M. Park, Advanced Composites '93, Wollongong, Australia, 1993, TMS, Warrendale, PA, 1993, p. 1265.

[6] A.M.S. Hamouda, M.S.J. Hashmi, Advanced Composites '93, Wollongong, Australia, 1993, TMS, Warrendale, PA, 1993, p. 1119.

[7] J.C. Huang, Y.S. Lo, G.T. Gray, J. Mater. Chem. Phys. 35 (1993) 71.

[8] S. Lee, K.M. Cho, K.C. Kim, W.B. Choi, Metall. Mater. Trans. 24A (1993) 895.

[9] C.G. Lee, D. Kwon, S. Lee, Scripta Metall. Mater. 30 (1994) 197.

[10] S.I. Hong, G.T. Gray, III, J.J. Lewandowski, Acta Metall. Mater. 41 (1993) 2337.

[11] C.C. Perng, J.R. Hwang, J.L. Doong, Mater. Sci. Eng. A171 (1993) 213.

[12] C.C. Perng, J.R. Hwang, J.L. Doong, Scripta Metall. Mater. 29 (1993) 311.

[13] R. Vaziri, D. Delfosse, G. Pageau, A. Poursartip, Int. J. Impact Eng. 13 (1993) 329.

[14] S.I. Hong, G.T. Gray, III, J. Mater. Sci. 29 (1994) 2987. 
[15] R.U. Vaidya, S.G. Song, A.K. Zurek, Philos. Magn. A 70 (1994) 819.

[16] R.U. Vaidya, A.K. Zurek, J. Mater. Sci. 30 (1995) 2541.

[17] S. Yadav, D.R. Chichili, K.T. Ramesh, Acta Metall. Mater. 43 (1995) 4453.

[18] B.Y. Lou, J.C. Huang, Metall. Mater. Trans. 27A (1996) 3095.

[19] M. Guden, I.W. Hall, Mater. Sci. Eng. A232 (1997) 1.

[20] A. Kalambur, I.W. Hall, Scripta Mater. 37 (1997) 193.

[21] M. Guden, I.W. Hall, Scripta Mater. 39 (1998) 261.

[22] M. Guden, I.W. Hall, Mater. Sci. Eng. A242 (1998) 141.

[23] S.C. Tjong, Z.Y. Ma, R.K.Y. Li, Mater. Lett. 38 (1999) 39.

[24] C.G. Lee, D. Kwon, S. Lee, Metall. Mater. Trans. 28A (1997) 2162.

[25] Y.W. Kwon, C.T. Liu, Mech. Res. Commun. 25 (1998) 329.

[26] Y.X. Lu, C.S. Lee, X.M. Meng, R.K.Y. Li, J. Mater. Sci. Lett. 18 (1999) 533.

[27] M.A. Irfan, V. Prakash, Int. J. Solids Struct. 37 (2000) 4477.

[28] Y. Li, K.T. Ramesh, E.S. Chin, Acta Mater. 48 (2000) 1563.

[29] H.W. Nam, G.A. Aggag, K. Takahashi, K.S. Han, Compos. Sci. Technol. 60 (2000) 817.

[30] L. Wang, T. Kobayashi, H. Toda, M. Hayakawa, Mater. Sci. Eng. A280 (2000) 214.

[31] L. Zhong, J. Compos. Mater. 34 (2000) 101.

[32] Y. Zhou, Y. Xia, Compos. Sci. Technol. 60 (2000) 403.

[33] G. Bao, Z. Lin, Acta Mater. 44 (1996) 1011.

[34] Y. Li, K.T. Ramesh, Acta Mater. 46 (1998) 5633.

[35] M. Kouzeli, L. Weber, C. San Marchi, A. Mortensen, Acta Mater. 49 (2001) 3699.

[36] J.A. Isaacs, F. Taricco, V.J. Michaud, A. Mortensen, Metall. Trans. 22A (1991) 2855.

[37] P.S. Follansbee, in: J.R. Newby (Ed.), The Metals Handbook Mechanical Testing, vol. 8, 9th ed., ASM International, Materials Park, OH, 1985, p. 198.

[38] U.S. Lindholm, J. Mech. Phys. Solids 12 (1964) 317.

[39] C.H. Karnes, E.A. Ripperger, J. Mech. Phys. Solids 14 (1966) 75.

[40] J.E. Hockett, Trans. Metall. Soc. AIME 239 (1967) 969.

[41] S. Yoshida, N. Nagata, Trans. Natl. Res. Inst. Metals 9 (1967) 20.

[42] D.L. Holt, S.G. Babcock, S.J. Green, C.J. Maiden, Trans. ASM 60 (1967) 152.

[43] U.F. Kocks, J. Eng. Mater. Technol.-Trans. ASME 98 (1976) 76.

[44] R. Kapoor, S. Nemat-Nasser, Mech. Mater. 27 (1998) 1.

[45] E.S. Puchi, M.H. Staia, C. Villalobos, Int. J. Plasticity 13 (1997) 723.

[46] M. Kouzeli, L. Weber, C. San Marchi, A. Mortensen, Acta Mater. 49 (2001) 497.

[47] W.S. Miller, F.J. Humphreys, Scripta Metall. Mater. 25 (1991) 33.

[48] S.V. Kamat, A.D. Rollett, J.P. Hirth, Scripta Metall. Mater. 25 (1991) 27.

[49] T.W. Gustafson, P.C. Panda, G. Song, R. Raj, Acta Mater. 45 (1997) 1633.
[50] N. Chawla, U. Habel, Y.-L. Shen, C. Andres, J.W. Jones, J.E. Allison, Metall. Mater. Trans. 31A (2000) 531.

[51] M. Kouzeli, A. Mortensen, Acta Mater. 50 (2002) 39.

[52] U.S. Lindholm, R.L. Bessey, G.V. Smith, J. Mater. 6 (1971) 119.

[53] U.S. Lindholm, in: J. Harding (Ed.), Conference on the Mechanical Properties of Materials at High Rates of Strain, Oxford, UK, 1974, The Insititute of Physics conference series no. 21, 1974, p. 3.

[54] T. Nicholas, in: J.A. Zukas (Ed.), Impact Dynamics, John Wiley \& Sons, New York, 1982, p. 277.

[55] T. Nicholas, A.M. Rajendran, in: J.A. Zukas (Ed.), High Velocity Impact Dynamics, John Wiley \& Sons, New York, 1990, p. 127.

[56] J. Harding, in: T.Z. Blazynski (Ed.), Materials at High Strain Rates, Elsevier Applied Science, London, 1987, p. 133.

[57] R.A. Frantz, J. Duffy, J. Appl. Mech.-Trans. ASME 39 (1972) 939.

[58] B. Viguier, A. Mortensen, Ultramicroscopy 87 (2001) 123.

[59] J. Yang, C. Cady, M.S. Hu, F. Zok, R. Mehrabian, A.G. Evans, Acta Metall. Mater. 38 (1990) 2613.

[60] M.S. Hu, Scripta Metall. Mater. 25 (1991) 695.

[61] S.I. Hong, Scripta Mater. 41 (1999) 433.

[62] A.F. Whitehouse, T.W. Clyne, Composites 24 (1993) 256.

[63] A.F. Whitehouse, T.W. Clyne, Acta Metall. Mater. 41 (1993) 1701.

[64] J.K. Mackenzie, Proc. R. Soc. Lond. B63 (1950) 2.

[65] Z.R. Xu, K.K. Chawla, A. Wolfenden, A. Newman, G.M. Ligget, N. Chawla, Mater. Sci. Eng. A203 (1995) 75.

[66] T. Mochida, M. Taya, D.J. Lloyd, Mater. Trans. JIM 32 (1991) 931.

[67] Y. Brechet, J.D. Embury, S. Tao, L. Luo, Acta Metall. Mater. 39 (1991) 1781.

[68] D.J. Lloyd, Acta Metall. Mater. 39 (1991) 59.

[69] Y. Brechet, J. Newell, S. Tao, J.D. Embury, Scripta Metall. Mater. 28 (1993) 47.

[70] J. Llorca, A. Martin, J. Ruiz, M. Elices, Metall. Trans. 24A (1993) 1575.

[71] J. Llorca, P. Poza, Mater. Sci. Eng. A185 (1994) 25.

[72] D.J. Lloyd, Int. Mater. Rev. 39 (1994) 1.

[73] J.Y. Yang, F.W. Zok, C.G. Levi, Processing, Properties and Applications of Cast Metal Matrix Composites, TMS, Warrendale, PA, 1996, p. 77.

[74] J. Liu, K. Schönert, Int. J. Miner. Process. 44-45 (1996) 101.

[75] D.W. Fuerstenau, O. Gutsche, P.C. Kapur, Int. J. Miner. Process. 44-45 (1996) 521.

[76] A.F. Whitehouse, T.W. Clyne, Acta Metall. Mater. 43 (1995) 2107.

[77] D.J. Lloyd, P.L. Morris, E. Nehme, Fabrication of Particulates Reinforced Metal Composites, ASM International, Materials Park, OH, 1990, p. 235.

[78] R.M. German, Particle Packing Characteristics, Metal Powder Industries Federation, Princeton, 1989, p. 443.

[79] J. Lankford, J. Am. Ceram. Soc. 64 (1981) C33. 